\title{
Crystallization behavior and high temperature magnetic phase transitions of $\mathrm{Nb}$-substituted FeCoSiBCu nanocomposites
}

\author{
R. K. Roy, ${ }^{1, \text { a) }}$ S. J. Kernion, ${ }^{2}$ S. Shen,${ }^{2}$ and M. E. McHenry ${ }^{2, a)}$ \\ ${ }^{1}$ CSIR-National Metallurgical Laboratory, Jamshedpur 831007, India \\ ${ }^{2}$ Department of Materials Science and Engineering, Carnegie Mellon University, Pittsburgh, \\ Pennsylvania 15213, USA
}

(Received 22 August 2011; accepted 19 October 2011; published online 9 November 2011)

\begin{abstract}
The effect of $\mathrm{Nb}$ substitution on the nanocrystallization process and high temperature magnetic properties of $\mathrm{FeCoSiBCu}$ nanocomposites is reported. Magnetization changes accompany the primary crystallization of $\alpha-\mathrm{Fe}(\mathrm{Co})$ nanocrystals and the secondary crystallization of $(\mathrm{FeCo})_{23} \mathrm{~B}_{6}$ and $(\mathrm{FeCo})_{2} \mathrm{~B}$ phases. With increasing the $\mathrm{Nb}$ fraction in the alloys, the diffusion barrier to growth of $\alpha-\mathrm{Fe}(\mathrm{Co})$ nanocrystals increases, resulting in an increase of thermal stability and a delay of $\mathrm{Fe}(\mathrm{Co})$ dissolution required for $(\mathrm{FeCo})_{23} \mathrm{~B}_{6}$ phase formation. The transmission electron microscopy images reveal finer grains with increasing $\mathrm{Nb}$ content. (C) 2011 American Institute of Physics. [doi:10.1063/1.3660245]
\end{abstract}

Since the discovery of FINEMET (FeSiBCuNb alloys), ${ }^{1}$ other soft magnetic nanocomposite alloys including NANOPERM (FeMBCu alloys; $\mathrm{M}=\mathrm{Zr}, \mathrm{Nb}, \mathrm{Hf})^{2}$ and HITPERM $(\mathrm{FeCoMBCu} \text { alloys })^{3}$ have been developed, which exhibit superior soft magnetic properties. However, the saturation magnetic flux density $\left(B_{S}\right)$ of these alloys is not as high as Sisteels. This has motivated recent research focusing on the development of Fe-based soft magnetic alloys with a high $\mathrm{B}_{\mathrm{S}} \cdot{ }^{4-6}$ These alloys exhibit the $\mathrm{B}_{\mathrm{S}}$ in the ranges of 1.24-1.58 T; however, their Curie temperatures and thermal stability are very low, which restrict their applications at high temperature.

FeCo based alloys, such as HITPERM, have shown high temperature magnetic properties because of their high Curie temperatures. ${ }^{7}$ Alloys with Fe:Co ratios of 50:50 and 65:35 exhibit a low magnetocrystalline anisotropy and a high $\mathrm{B}_{\mathrm{S}}$, respectively. ${ }^{3,8-11}$ In prior research, we have observed the crystallite size to become finer with the addition of $\mathrm{Nb}$, resulting in the development of materials with a low core loss. ${ }^{12}$ The nanocrystallization process of HITPERM alloys is quite different than that of FINEMET alloys. ${ }^{13}$ It is reported that $\mathrm{Cu}$ clustering is strongly reduced in FINEMET alloys by the substitution of $\mathrm{Fe}$ by $\mathrm{Co},{ }^{14}$ and no $\mathrm{Cu}$ clusters are observed in HITPERM alloy $\mathrm{Fe}_{44} \mathrm{Co}_{44} \mathrm{Zr}_{7} \mathrm{~B}_{4} \mathrm{Cu}_{1} .{ }^{7}$ However, $\mathrm{Cu}$ clusters have been observed in the $\mathrm{Nb}$ containing HITPERM alloy of composition $\mathrm{Fe}_{39} \mathrm{Co}_{39} \mathrm{Nb}_{6} \mathrm{~B}_{15} \mathrm{Cu}_{1}$, ${ }^{15}$ although in other Co-rich alloys the density of $\mathrm{Cu}$ clusters is insufficient to explain the copious nucleation in these alloys. The focus of this research is to investigate the effect of $\mathrm{Nb}$ on the nanocrystallization reaction and consequent high temperature magnetic properties.

Ribbons ( $\mathrm{Nb} 0$, \#Nb1, \#Nb2, and \#Nb3) of nominal composition $\left(\mathrm{Fe}_{0.65} \mathrm{Co}_{0.35}\right)_{85-\mathrm{x}} \mathrm{Si}_{2.8} \mathrm{~B}_{11.2} \mathrm{Nb}_{\mathrm{x}} \mathrm{Cu}_{1}$ with the varying $\mathrm{Nb}$ contents $(\mathrm{x}=0,1,2$, and 3$)$ were prepared by a single roller melt spinning. The Fe:Co ratio was kept at 65:35 to achieve optimum saturation magnetic flux density. The thermal behavior of ribbons was studied using differential scan-

\footnotetext{
a) Authors to whom correspondence should be addressed. Electronic addresses: rajat@nmlindia.org and mm7g@andrew.cmu.edu. Telephone: $+91-657-2345002$ and $+01-412-2682703$.
}

ning calorimetry (DSC) employing a Perkin Elmer DSC7. The structure of as-quenched and annealed samples was determined by $\mathrm{x}$-ray diffraction (XRD) of Panalytical (X'Pert PRO) and transmission electron microscopy (TEM) of JEOL (JEM-2000EX-II). The saturation magnetic flux density $\left(B_{S}\right)$ under a maximum applied field of $800 \mathrm{kA} / \mathrm{m}$ and the variation of magnetization $(\mathrm{M})$ with temperature were measured by a Lakeshore vibrating sample magnetometer (VSM). The coercivity of annealed alloys was determined from dc B-H curve measured with a B-H curve tracer.

The metastability of amorphous phase of FeCo-based as-quenched alloys increases with $\mathrm{Nb}$ addition. The XRD patterns of \#Nb3 and \#Nb2 alloys exhibit only broad peaks, confirming the formation of a single amorphous phase. The structure becomes hetero-amorphous with the dispersion of nuclei in amorphous matrix for 1 at. \% $\mathrm{Nb}$ (\#Nb1) and $\mathrm{Nb}$ free (\#Nb0) alloys. The $\mathrm{Nb}$ content dependencies of thermal and magnetic properties are shown in Figs. 1(a)-1(d). The primary crystallization of an $\alpha-\mathrm{Fe}(\mathrm{Co})$ phase and the secondary crystallization of intermetallic boride and niobide compounds are observed in all alloys. The onset primary and secondary crystallization temperatures, $\mathrm{T}_{\mathrm{X} 1}$ and $\mathrm{T}_{\mathrm{X} 2}$, of alloy \#Nb0 are 370 and $526{ }^{\circ} \mathrm{C}$, respectively (Fig. 1(a)). The $\mathrm{Nb}$ additions to the \#Nb0 alloy shift both $\mathrm{T}_{\mathrm{X} 1}$ and $\mathrm{T}_{\mathrm{X} 2}$ to higher temperatures and increase the difference $\left(\Delta \mathrm{T}_{\mathrm{X}}\right)$ between two onset temperatures (Fig. 1(b)). Therefore, the thermal stability is gradually enhanced for \#Nb1, \#Nb2, and \#Nb3 alloys. The wider $\Delta \mathrm{T}_{\mathrm{X}}$ allows for the formation of nanocrystallites in the residual amorphous matrix without secondary crystallization by annealing between $\mathrm{T}_{\mathrm{X} 1}$ and $\mathrm{T}_{\mathrm{X} 2}$, which is preferable in soft ferromagnetic nanocomposites. The $\Delta \mathrm{T}_{\mathrm{X}}$ of these alloys is higher than previously reported $\mathrm{Fe}$-based magnetic alloys. ${ }^{4-6}$ The magnetic flux density $\left(\mathrm{B}_{\mathrm{s}}\right)$ is $1.54 \mathrm{~T}$ for the alloy \#Nb3 and increases with the substitution of ferromagnetic elements for $\mathrm{Nb}$ (Fig. 1(c)), as also recently reported for other HITPERM alloys. ${ }^{16}$ On the other hand, the coercivity of annealed $\left(450{ }^{\circ} \mathrm{C}\right)$ alloys decreases with $\mathrm{Nb}$ addition, reaching its minimum of about $70 \mathrm{~A} / \mathrm{m}$ for \#Nb3 alloy (Fig. 1(d)). The enhancement of soft magnetic properties with $\mathrm{Nb}$ addition is comparable with other $\mathrm{FeCoBSiCu}$ alloys. ${ }^{12}$ 


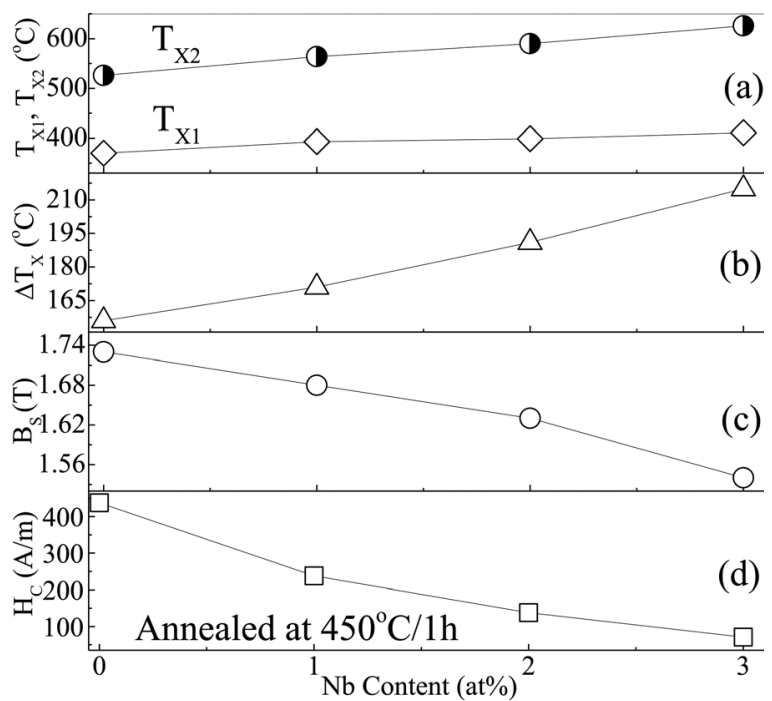

FIG. 1. Nb content dependencies of (a) $\mathrm{T}_{\mathrm{X} 1}, \mathrm{~T}_{\mathrm{X} 2}$, (b) $\Delta \mathrm{T}_{\mathrm{X}}$, (c) $\mathrm{B}_{\mathrm{S}}$ and (d) $\mathrm{H}_{\mathrm{C}}$.

Fig. 2 shows VSM derived magnetic transitions occurring in devitrification of amorphous ferromagnetic alloys. The magnetization of alloys has minimum values at temperatures, labeled $\mathrm{T}_{\mathrm{c} 1}, \mathrm{~T}_{\mathrm{c} 2}$, and $\mathrm{T}_{\mathrm{c} 3}$. These temperatures are explained as follows:

(1) The magnetization of starting amorphous phase is a monotonically decreasing function of temperature, disappearing in a second order phase transition at its Curie temperatures.

(2) The sample's thermodynamic state changes as new ferromagnetic phases are formed in each crystallization event. The temperature, $\mathrm{T}_{\mathrm{c} 1}$, and the primary crystallization temperature, $\mathrm{T}_{\mathrm{X} 1}$, coincide for all alloys. The decrease in magnetization follows the intrinsic $\mathrm{M}(\mathrm{T})$ behavior in the as-quenched amorphous phase. The increase in magnetization after $\mathrm{T}_{\mathrm{c} 1}$ corresponds to the formation of $\alpha-\mathrm{Fe}(\mathrm{Co})$ nanocrystals with larger magnetizations in primary crystallization. The stabilization of amorphous phase by $\mathrm{Nb}$ addition delays primary crystallization, resulting in an increase of $\mathrm{T}_{\mathrm{c} 1}$ for \#Nb1, \#Nb2, and \#Nb3 alloys.

(3) The composition change in nanocrystallization acts to increase the relative concentration of glass formers in the amorphous matrix and consequently decreases the net dipole moment in this phase. The amorphous phase

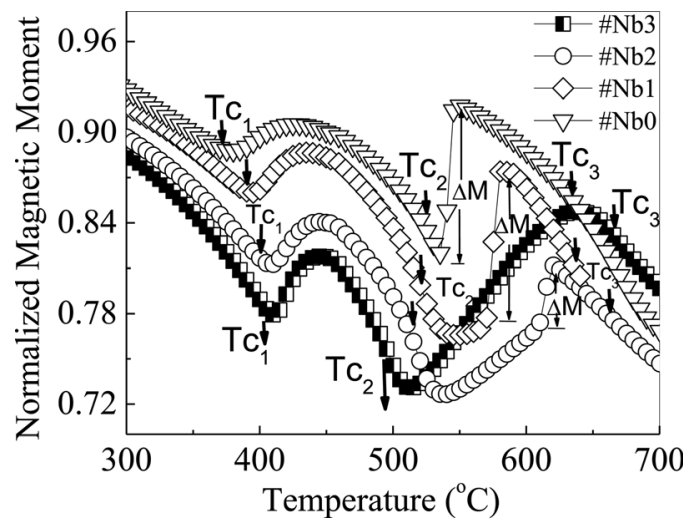

FIG. 2. Magnetization of as-quenched alloys as a function of temperature. magnetization continues to decrease with temperature, disappearing at $\mathrm{T}_{\mathrm{c} 2}$ which is the Curie temperature of residual amorphous phase.

(4) $\mathrm{T}_{\mathrm{c} 3}$ is associated with secondary crystallization of $(\mathrm{FeCo})_{23} \mathrm{~B}_{6}$ phases. $^{16-18}$

The composition variation in amorphous matrix during the nanocrystallization process is a complex function of the enrichment in $\mathrm{B}$ and $\mathrm{Nb}$ and increases in the $\mathrm{Co} /(\mathrm{Fe}+\mathrm{Co})$ ratio. The magnetic properties are thus correlated with nanocrystallites formation in amorphous matrix. ${ }^{13}$ Although the Co concentration is homogeneous throughout the amorphous matrix and nanocrystals, the nanocrystals are enriched with Fe relative to the matrix and expel $\mathrm{Nb}$ and $\mathrm{B}$ to the matrix during crystallization. ${ }^{15}$ The enrichment of matrix with $\mathrm{Nb}$ and B stabilizes the residual amorphous phase. Moreover, due to low diffusivity and solubility of $\mathrm{Nb}$ in $\mathrm{Fe}(\mathrm{Co})$ phases, $\mathrm{Nb}$ acts as a diffusion barrier located at the primary nanocrystal/amorphous matrix interface. The thickness of the diffusion barrier increases with increasing $\mathrm{Nb}$ percentage for fixed B containing alloys. Consequently, it hinders primary nanocrystal grain growth and also restricts Fe enrichment in $\mathrm{Fe}(\mathrm{Co})$ phases, resulting in the increase of Fe content in the amorphous matrix.

It is interesting to note that the $\mathrm{T}_{\mathrm{c} 2}$ of $\mathrm{Nb}$ containing alloys gradually decreases with $\mathrm{Nb}$ percentage as compared with the $\mathrm{Nb}$ free alloy (\#Nb0). Since $\mathrm{Nb}$ acts as a diffusion barrier in $\mathrm{Fe}(\mathrm{Co})$ crystals, the stability of residual amorphous matrix decreases, influencing a decrease of $\mathrm{T}_{\mathrm{c} 2}$ with the addition of $\mathrm{Nb}$. The stabilizing effect of $\mathrm{Nb}$ on the secondary crystallization product, the 23:6 phase, has been previously postulated and supported by band theory calculations. ${ }^{15,19}$ At large enough annealing times or temperatures, the volume fraction of $\mathrm{Fe}(\mathrm{Co})$ crystallites decreases as it recrystallizes into nonmagnetic $(\mathrm{FeCo})_{23} \mathrm{~B}_{6}$ phases. ${ }^{15,17}$ Moreover, the dissolution of $\mathrm{Fe}(\mathrm{Co})$ phases is retarded due to the $\mathrm{Nb}$ impingement, and the $\mathrm{T}_{\mathrm{X} 2}$ for $(\mathrm{FeCo})_{23} \mathrm{~B}_{6}$ phase formation shifts to higher temperature for $\mathrm{Nb}$ added alloys. The transformation of residual amorphous phase to $\mathrm{Fe}(\mathrm{Co})$ nanocrystallites is the reason for increasing the magnetic moment after $\mathrm{T}_{\mathrm{c} 2}$. It is noteworthy that the sudden jump of magnetization $(\Delta M)$ after $\mathrm{T}_{\mathrm{c} 2}$ progressively decreases with increasing $\mathrm{Nb}$ percentage and it diminishes completely for \#Nb3 alloy which shows a gradual increase of magnetization at post $\mathrm{T}_{\mathrm{c} 2}$ temperature. This behavior is attributed to the restricted grain growth of nanocrystallites and, therefore, delaying the $\mathrm{Nb}$ dissolution from $\mathrm{Fe}(\mathrm{Co})$ crystallites for $(\mathrm{FeCo})_{23} \mathrm{~B}_{6}$ phase formation.

Structural characterization by XRD and TEM identifies the phases present and their morphologies for different annealing conditions. Figure 3 shows XRD patterns of alloys annealed for $1 \mathrm{~h}$ at different temperatures. After the completion of primary crystallization, the alloys have $\alpha-\mathrm{Fe}(\mathrm{Co})$ nanocrystallites distributed in a residual amorphous matrix. On further annealing, the atomic redistribution results in a decrease of residual amorphous matrix and the formation of secondary crystals. The weakly magnetic phases, $(\mathrm{FeCo})_{23} \mathrm{~B}_{6}$ and $(\mathrm{FeCo})_{2} \mathrm{~B}$, are seen in alloys \#Nb0, \#Nb1, and \#Nb2 annealed at 500,550 , and $550{ }^{\circ} \mathrm{C}$, respectively. These temperatures are lower than the secondary crystallization 


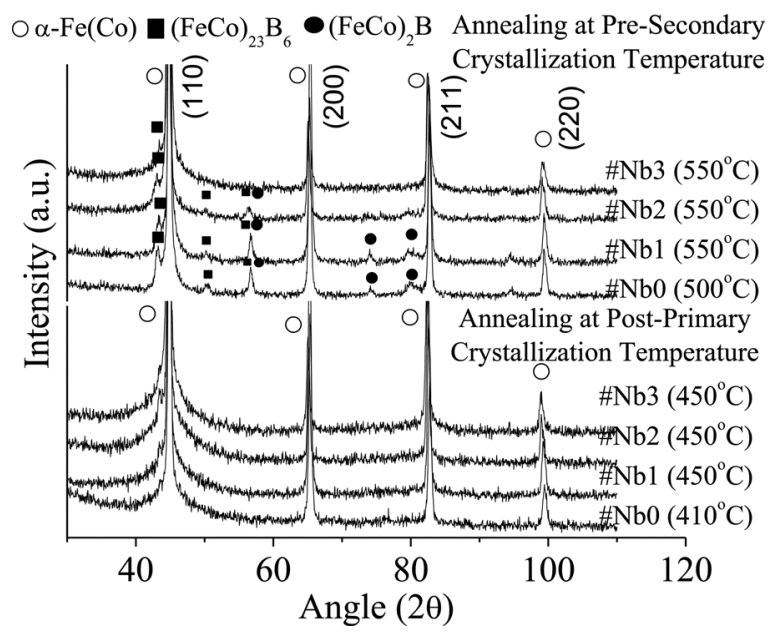

FIG. 3. XRD patterns of \#Nb0, \#Nb1, \#Nb2, and \#Nb3 alloys annealed at different temperatures for $1 \mathrm{~h}$.

temperature $\left(\mathrm{T}_{\mathrm{X} 2}\right)$ found by DSC for those alloys. This is due to low thermal stability of the alloys, which leads to an early dissolution of $\alpha-\mathrm{Fe}(\mathrm{Co})$ crystallites and the formation of second phases within $1 \mathrm{~h}$ annealing of that specific temperature. Alternatively, the high thermal stability and the low dissolution of $\alpha-\mathrm{Fe}(\mathrm{Co})$ crystallites restrict the formation of second phases in the alloy \#Nb3, annealed at $550{ }^{\circ} \mathrm{C}$ for $1 \mathrm{~h}$. The higher heating rate may be another reason for increasing $\mathrm{Tx}_{2}$ in DSC thermograms.

The microstructural change occurred due to secondary crystallization has been verified by TEM, as shown in Fig. 4. Alloys, \#Nb2 and \#Nb3, annealed at $550^{\circ} \mathrm{C}$ show a homogeneous dispersion of nanocrystallites in the amorphous matrix and many smaller particles embedded with larger particles. As observed from selected area diffraction patterns (shown in insets), the $\alpha-\mathrm{Fe}(\mathrm{Co})$ ring is common for both alloys, whereas an extra ring is examined in \#Nb2 alloy due to the formation of $(\mathrm{FeCo})_{23} \mathrm{~B}_{6}$ phase. The diffraction patterns of \#Nb2 are combined with spots and rings where as the alloy \#Nb3 shows only ring patterns, signifying the generation of more coarse grains in the former alloy. The measured average grain size of \#Nb2 (32 nm) is also larger than that of

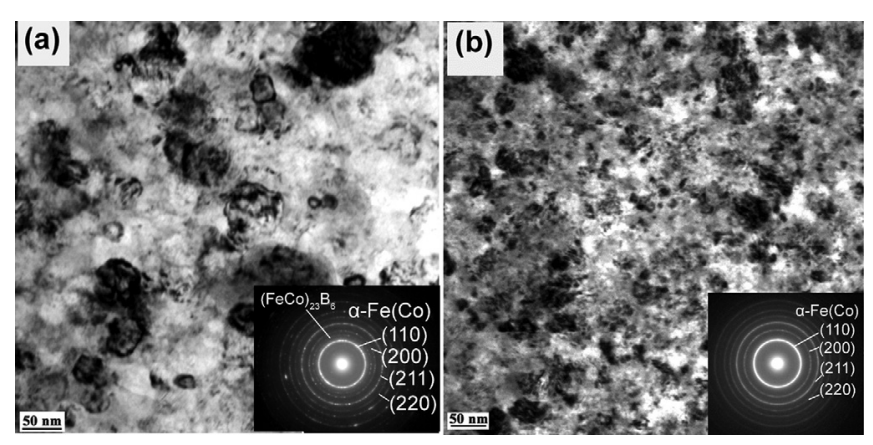

FIG. 4. Bright field TEM images of alloys (a) \#Nb2 and (b) \#Nb3, annealed at $550{ }^{\circ} \mathrm{C}$ for $1 \mathrm{~h}$.
\#Nb3 $(20 \mathrm{~nm})$. The absence of $(\mathrm{FeCo})_{23} \mathrm{~B}_{6}$ phase and the formation of finer grains in \#Nb3 alloy are due to the hindrance of grain growth with the effect of higher $\mathrm{Nb}$ content.

In conclusion, with increasing the $\mathrm{Nb}$ content, the amorphization of $\left(\mathrm{Fe}_{0.65} \mathrm{Co}_{0.35}\right)_{85-\mathrm{x}} \mathrm{Si}_{2.8} \mathrm{~B}_{11.2} \mathrm{Nb}_{\mathrm{x}} \mathrm{Cu}_{1}$ alloys increases, converting from hetero-amorphous structure to amorphous structure. The higher $\mathrm{Nb}$ content also increases the thermal stability with the effect of diffusion barrier at the primary nanocrystal/amorphous matrix interface, slowing down the dissolution of $\alpha-\mathrm{Fe}(\mathrm{Co})$ crystallites for $(\mathrm{FeCo})_{23} \mathrm{~B}_{6}$ phase formation. It also restricts the grain growth behavior, resulting in the generation of $20 \mathrm{~nm}$ crystallites for 3 at. $\% \mathrm{Nb}$ alloy compared to $32 \mathrm{~nm}$ crystallites for 2 at. $\% \mathrm{Nb}$ alloy. The lowering of crystalline grain size is responsible for the improvement of soft magnetic properties of the \#Nb3 alloy.

R.K. Roy acknowledges to Department of Science and Technology (DST), Government of India and Director, CSIR-NML, for conducting this research under the BOYSCAST fellowship. The authors would also like to acknowledge support from the ARL through Grant No. W911NF-08-2-0024 and Dr. Adam Wise for his help in obtaining TEM images.

${ }^{1}$ Y. Yoshizawa, S. Oguma, and K. Yamauchi, J. Appl. Phys. 64, 6044 (1988).

${ }^{2}$ K. Suzuki, A. Makino, N. Kataoka, A. Inoue, and T. Masumoto, Mater. Trans. JIM 32, 93 (1991).

${ }^{3}$ M. A. Willard, D. E. Laughlin, M. E. McHenry, D. Thoma, K. Sickafus, J. O. Cross, and V. G. Harris, J. Appl. Phys. 84, 6773 (1998).

${ }^{4}$ A. Urata, H. Matsumoto, S. Yoshida, and A. Makino, J. Alloy Compd. 509, S431 (2011).

${ }^{5}$ A. Makino, H. Men, K. Yubuta, and T. Kubota, J Appl. Phys. 105, 013922 (2009).

${ }^{6}$ T. Kubota, A. Makino, and A. Inoue, J. Alloy Compd. 509, S416 (2011).

${ }^{7}$ D. H. Ping, Y. Q. Wu, K. Hono, M. A. Willard, M. E. McHenry, and D. E. Laughlin, Scr. Mater. 45, 781 (2001).

${ }^{8}$ H. Iwanabe, B. Lu, M. E. McHenry, and D. E. Laughlin, J. Appl. Phys. 85, 4424 (1999).

${ }^{9}$ P. R. Ohodnicki, S. Y. Park, D. E. Laughlin, M. E. McHenry, V. Keylin, and M. A. Willard, J. Appl. Phys. 103, 07 E729 (2008).

${ }^{10}$ P. R. Ohodnicki, H. McWilliams, D. E. Laughlin, M. E. McHenry, and V. Keylin, J. Appl. Phys. 103, 07E740 (2008).

${ }^{11}$ A. K. Panda, O. Mohanta, A. Kumar, M. Ghosh, and A. Mitra, Philos. Mag. 87, 1671 (2007).

${ }^{12}$ K. J. Miller, A. Leary, S. J. Kernion, A. Wise, D. E. Laughlin, M. E. McHenry, V. Keylin, and J. Huth, J. Appl. Phys. 107, 09A316 (2010).

${ }^{13}$ M. E. McHenry, F. Johnson, H. Okumura, T. Ohkubo, A. Hsiao, V. R. V. Ramanan, and D. E. Laughlin, Scr. Mater. 48, 881 (2003).

${ }^{14} \mathrm{~K}$. Hono, Advanced Magnetic Materials: Characterization and Simulation of Advanced Magnetic Materials, edited by Y. Liu, D. J. Sellmyer, D. Shindo, J. G. Zhu, and G. C. Hadjipanayis (Springer-Verlag, Berlin, 2002).

${ }^{15}$ Y. Zhang, J. S. Blázquez, A. Conde, P. J. Warren, and A. Cerezo, Mater. Sci. Eng., A 353, 158 (2003).

${ }^{16}$ S. J. Kernion, K. J. Miller, S. Shen, V. Keylin, J. Huth, and M. E. McHenry, IEEE Trans. Mag. 47, 3452 (2011).

${ }^{17}$ J. S. Blázquez, C. F. Conde, and A. Conde, Appl. Phys. Lett. 79, 2898 (2001).

${ }^{18}$ J. Long, P. R. Ohodnicki, D. E. Laughlin, M. E. McHenry, T. Ohkubo, and K. Hono, J. Appl. Phys. 101, 09N114 (2007).

${ }^{19}$ P. R. Ohodnicki, N. C. Cates, D. E. Laughlin, M. E. McHenry, and M. Widom, Phys. Rev. B 78, 144414 (2008). 